\author{
Animal Review \\ 2021 Vol. 8, No. 1, pp. 20-29. \\ $\operatorname{ISSN}(e): 2409-6490$ \\ $\operatorname{ISSN}(p): 2412-3382$ \\ DOI: 10.18488/journal.ar.2021.81.20.29 \\ (C) 2021 Conscientia Beam. All Rights Reserved. \\ check for
updates
}

\title{
EFFECT OF PRE-STORAGE HEATING AND PERIOD OF STORAGE ON HATCHABILITY TRAITS OF DOKKI-4 EGGS
}

\author{
Sherif, Kh. El ${ }^{1}$ \\ El-Gogary, M. R. ${ }^{2}$ \\ Hasan, R.A. ${ }^{3}$ \\ Ismail, F. Radwa ${ }^{4+}$
}

\author{
${ }^{1,2,4}$ Poultry Production Department, Faculty of Agriculture, Mansoura \\ University, Mansoura, Egypt. \\ 'Email: sherief2015@yahoo.com \\ ${ }^{4}$ Email:braveheartagric@yahoo.com \\ ${ }^{s}$ Animal Production Research Institute, Ministry of Agriculture, Dokki, \\ Cairo, Egypt.
}

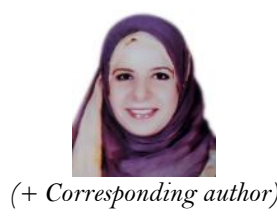

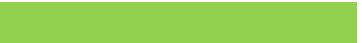

Article History

Received: 6 August 2021 Revised: 10 September 2021 Accepted: 21 September 2021 Published: 26 October 2021

\section{Keywords}

Pre-storage heating

Eggs

Storage period

Hatchability

Chick quality

Laying hens.

\section{ABSTRACT}

This study investigated the effects of pre-storage heating and storage period of hatching eggs on hatchability traits and chick quality of Dokki-4 (Egyptian local strain of chickens) laying hens. A total of 3600 eggs were collected from 46-week-old laying hens. Eggs were distributed in a $3 \times 4$ factorial arrangement, with three storage times $(4$, 8 and 12 days at $18^{\circ} \mathrm{C}$ and $\left.75 \% \mathrm{RH}\right)$ and four heat treatments prior to storage $(0,3,6$ and 9 hours at $37.5^{\circ} \mathrm{C}$ and $\left.56 \% \mathrm{RH}\right)$. Eggs were distributed to twelve treatments of 20 replicates. After storage, eggs were incubated under the normal conditions of incubation at the same time. The results showed that the long storage period increased egg weight loss. Hatchability and chick quality results from 8-12 days stored eggs were lower than eggs stored for 4 days. The 6 -hour pre-storage heating system substantially improved egg hatchability and chick quality relative to non-heated or 9-hour heating. Important interactions were observed during pre-storage heating $\times$ egg storage time for loss in egg weight, hatchability of total and fertile eggs, embryonic mortality and chick quality. When eggs were stored for more than four days, pre-storage heating of hatching eggs for six hours improved hatchability and chick quality compared to unheated eggs or heated for 9 hours. Conclusively, pre-storage heat treatment beneficially affects hatchability traits and chick quality, especially when hatching eggs are stored for long periods.

Contribution/Originality: This study contributes to existing literature by investigating the effects of prestorage heating and storage period of hatching eggs on hatchability traits and chick quality of Dokki-4 (Egyptian local strain of chickens) laying hens.

\section{INTRODUCTION}

Cooling of hatching eggs before incubation is common practice in poultry industry. It is well known that incubation length increases when the storage period is more than seven days $[1,2]$ and this may had adverse effects on hatchability $[3,4]$ and chick quality [1, 4]. Furthermore, previous reports have established the adverse effects of long storage period on embryos development and viability, hatching rate [1,5]. Many publications have shown that storage of hatching eggs for long period decreased egg hatchability in aged breeder hens more than in young breeder hens $[4,5]$. It was suggested that the adverse effects of long storage period of eggs could be attributed to the deterioration of egg quality, primarily albumen quality [6]. In this regard, Lapao, et al. [5] found that albumen $\mathrm{pH}$ was raised with increasing storage period. Albumen height was also decreased with increasing egg storage 
period [5]. Also, Jones and Musgrove [7] yolk sac membrane elasticity decreased as storage time increased. Nahm [8] found that mortality of chicken embryos during storage was strongly related to length of storage. Warming of hatching eggs prior to storage was suggested as a managerial strategy for reducing the negative effects of long storage periods via improving the embryonic development. Fasenko, et al. [3] and Gucbilmez, et al. [9] suggested a correlation between pre-storage heat treatment and improved hatchability of chicken eggs. The same relationship was observed in turkeys [10] and quails [11]. Hamidu, et al. [12]; Hamidu, et al. [13] and Dymond, et al. [14] found that prolonged storage of hatching eggs can cause embryonic stress, leading to increased embryonic mortality, depressed embryonic metabolism, and impaired development. Therefore, it could be assumed that prestorage incubation might accelerate the embryonic development and enhance the viability of the developing embryos. The present study therefore aimed to investigate the effects of pre-storage heating and storage period of hatching eggs on hatchability and chick quality of Dokki-4 laying hens.

\section{MATERIALS AND METHODS}

This study was performed at Sakha Research Station, Animal Production Research Institute, Ministry of Agriculture, Egypt.

\subsection{Experimental Design and Treatments}

In this trial, 3600 hatching eggs were collected from Dokki-4 chicken hens (Egyptian local strain of chickens) at 42 weeks old which maintained under similar environment and management conditions (male: female ratio was 1:10). Light schedule included $16 \mathrm{~h}$ of light and $8 \mathrm{~h}$ of darkness). The eggs were distributed in a $3 \mathrm{x} 4$ factorial design, three storage periods $\left(4,8\right.$ and 12 days at $17^{\circ} \mathrm{C}$ and $75 \%$ relative humidity) and four incubation times prior to storage $\left(0,3,6\right.$ and 9 hours at $37.5^{\circ} \mathrm{C}$ and $56 \%$ relative humidity), summing up 12 treatments with 20 replicates of 15 eggs each. In order to simultaneously incubate all eggs, the eggs were collected in three groups, one group per day, representing the three storage periods (4, 8 and 12 days). The first category therefore corresponded to eggs stored for twelve days; the second to eggs stored for eight days, and the third to eggs stored for 12 days.

\subsection{General Management}

Immediately after collection, the eggs was fumigated by paraformaldehyde gas [15] through the interaction of $35 \mathrm{ml}$ formalin, 17.5 grams of potassium permanganate and $50 \mathrm{ml}$ of warm water per cubic meter of the volume of evaporation room for 30 minutes then it was ventilated chamber by fresh air through the operation the air fan and opening the windows for about an hour to get rid of the residues of paraformaldehyde gas. All eggs in each group were individually weighed, numbered and randomly distributed into the treatments. The heating timing started when the temperature reached $37.5^{\circ} \mathrm{C}$ and the relative humidity $56 \%$ inside hatchery. After heating, eggs were kept for one hour at room temperature, then eggs stored at $17^{\circ} \mathrm{C}$ in a storage room and 75 percent relative humidity for the periods corresponding to the treatments. After storage, the eggs were kept at $25^{\circ} \mathrm{C}$ and $75 \%$ relative humidity for six hours before incubation, then incubated at a temperature of $37.5{ }^{\circ} \mathrm{C}$ and relative humidity of $56.5 \%$ for 18 days in a Chick Master incubator. After that, eggs were transferred to a Chick Master ${ }^{\circledR}$ hatcher at $36.6^{\circ} \mathrm{C}$ temperature and $61.2 \%$ (relative humidity).

\subsection{Measurements}

\subsubsection{Egg Weight Loss}

Egg weight loss was calculated individually twice at the end of storage period and at day 18 of incubation. Egg weight loss during storage was determined as the difference in egg weight between initial egg weight (at the day of egg collection) and the last day of storage as a percentage of egg weight at collection. Egg weight loss during incubation was determined as the difference in egg weight between the last day of storage and day 18 of incubation 
as a percentage of egg weight at the last day of storage. Total egg weight loss was the sum of egg weight loss during storage and incubation.

\subsubsection{Embryonic Mortality}

At 7 and 14 days of incubation all eggs were candled, and all clear eggs were removed from the trays. At the end of 18 day of incubation, all eggs were candled again and those with evidence of living embryos were transferred from the setter trays to the hatcher trays. [16] categorized the embryonic mortality into three categories: early from days 1 to 7 , middle from days 8 to 14 and late from days 15 to 21 .

\subsubsection{Piped Eggs}

The formula referenced by Lourens [17] was applied in determining the rate of Piped eggs: Rate of Piped eggs \% = Number of piped eggs / Number of fertilized eggs* 100

\subsubsection{Fertility and Hatchability}

Fertility was calculated as total fertile eggs as a percentage of total eggs set into the incubator. Hatchability was calculated as a percentage of fertile eggs and total eggs set.

\subsubsection{Chick Quality}

All the chicks were classified to first grade 'A' and second grade "B.'. A chick was grouped in grade A when it was completely healthy, clean, dry, free of deformities, with bright eyes [4]. The other chicks were classified in grade $\mathrm{B}$. The chicks in both grades were expressed as a percentage of total hatched chicks.

\subsubsection{Chick Length}

Twenty chicks randomly selected from each treatment for individual measurement of chick length (cm) directly after hatch. The length of the chick was described as the length from the beak tip to the nail implantation on the middle toe [18].

\subsection{Statistical Analysis}

Program of SAS [19] was used to statistical analysis of the data according to a factorial experiment $(3 \times 4)$ applied in a complete randomized design (CRD) to study the effect of three storage periods of eggs and four incubation time prior to storage eggs and their interference in different qualities. The differences between the averages were compared [20].

$\mathrm{Y}_{\mathrm{ijk}}=\mu+\mathrm{S}_{\mathrm{i}}+\mathrm{H}_{\mathrm{j}}+\mathrm{S}_{\mathrm{ij}}+\mathrm{E}_{\mathrm{ijk}}$

$\mu=$ Overall mean.

$\mathrm{Si}=$ Effect of storage period $(\mathrm{I}=1,2,3)$.

$\mathrm{Hj}=$ Effect of incubation time prior to storage of eggs $(\mathrm{j}=1,2,3,4)$.

$\mathrm{S}_{\mathrm{ij}}=$ Interaction between storage period and incubation time before storage.

$\mathrm{E}_{\mathrm{ijk}}=$ Residual error.

\section{RESULTS}

\subsection{Egg Weight Loss (LEW)}

In Table 1, mean percentage of LEW during storage, first eighteen days of incubation and total LEW were significantly higher for longer storage period (12 days) compared to the shorter periods ( 4 and 8 days). In the interaction between storage duration and pre-incubation periods, as pre-incubation periods increased, incremental increase with substantial impact in the percentage of egg weight loss was observed across all the periods studied. 
Group of eggs that incubated for 9 hours before 12 days of storage had the highest and most important percentage of egg weight loss during storage, first eighteen days of incubation and total percentage of egg weight loss compared to the other groups and the lowest one with significant value was reported for egg group that was not incubated before storage of 4 days.

Table-1. The effects of storage period, pre-storage incubation and their interaction on fresh egg weight and egg weight loss percentage of Dokki4 eggs.

\begin{tabular}{|c|c|c|c|c|}
\hline \multirow[b]{2}{*}{ Treatments } & \multicolumn{4}{|c|}{ Traits } \\
\hline & $\begin{array}{l}\text { Fresh egg } \\
\text { weight }(g)\end{array}$ & $\begin{array}{l}\text { Egg weight loss } \\
\text { during storage, \% }\end{array}$ & $\begin{array}{c}\text { Egg weight loss after } 18 \\
\text { days of incubation, \% }\end{array}$ & $\begin{array}{c}\text { Total egg } \\
\text { loss, \% }\end{array}$ \\
\hline \multicolumn{5}{|c|}{ Egg storage period (days) } \\
\hline 4 & 50.42 & $0.84^{\mathrm{C}}$ & $10.57^{\mathrm{C}}$ & $11.41^{\mathrm{C}}$ \\
\hline 8 & 50.45 & $1.17^{\mathrm{B}}$ & $11.62^{\mathrm{B}}$ & $12.80^{\mathrm{B}}$ \\
\hline 12 & 50.50 & $1.52^{\mathrm{A}}$ & $12.51^{\mathrm{A}}$ & $14.03^{\mathrm{A}}$ \\
\hline SEM & 0.0562 & 0.0639 & 0.2020 & 0.2593 \\
\hline p-value & 0.865 & 0.0001 & 0.0001 & 0.0001 \\
\hline \multicolumn{5}{|c|}{ Pre-storage incubation (hours at $37.5^{\circ} \mathrm{c}$ ) } \\
\hline $\mathrm{O}$ & 50.50 & $0.83^{\mathrm{C}}$ & $10.73^{\mathrm{C}}$ & $11.56^{\mathrm{C}}$ \\
\hline 3 & 50.43 & $1.20^{\mathrm{B}}$ & $11.84^{\mathrm{AB}}$ & $13.04^{\mathrm{B}}$ \\
\hline 6 & 50.53 & $1.17^{\mathrm{B}}$ & $10.98^{\mathrm{BC}}$ & $12.15^{\mathrm{BC}}$ \\
\hline 9 & 50.36 & $1.5 \mathrm{O}^{\mathrm{A}}$ & $12.73^{\mathrm{A}}$ & $14.24^{\mathrm{A}}$ \\
\hline SEM & 0.0562 & 0.0639 & 0.2020 & 0.2593 \\
\hline p-value & 0.747 & 0.001 & 0.0001 & 0.0001 \\
\hline \multicolumn{5}{|c|}{ Interaction between storage period and pre-storage incubation } \\
\hline 4 days $*$ o hours & 50.50 & $0.63^{\mathrm{e}}$ & $10.06^{\mathrm{h}}$ & $10.69 \mathrm{~g}$ \\
\hline 4 days $* 3$ hours & 50.30 & $0.88^{\mathrm{d}}$ & $10.34^{\mathrm{gh}}$ & $11.22^{\mathrm{fg}}$ \\
\hline 4 days $* 6$ hours & 50.50 & $0.76^{\text {de }}$ & $10.10^{\mathrm{h}}$ & $10.86^{\mathrm{fg}}$ \\
\hline 4 days $* 9$ hours & 50.40 & $1.10^{\mathrm{c}}$ & $11.80^{\text {de }}$ & $12.90^{\mathrm{cd}}$ \\
\hline 8 days $*$ o hours & 50.40 & $0.82^{\mathrm{d}}$ & $10.80^{\text {fgh }}$ & $11.62^{\mathrm{ef}}$ \\
\hline 8 days $* 3$ hours & 50.50 & $1.15^{\mathrm{c}}$ & $12.06^{\mathrm{cd}}$ & $13.21^{\mathrm{c}}$ \\
\hline 8 days $* 6$ hours & 50.50 & $1.20^{\mathrm{c}}$ & $11.05^{\mathrm{efg}}$ & $12.25^{\mathrm{de}}$ \\
\hline 8 days $* 9$ hours & 50.40 & $1.52^{\mathrm{b}}$ & $12.60^{\mathrm{bc}}$ & $14.12^{\mathrm{b}}$ \\
\hline 12 days $*$ o hours & 50.60 & $1.05^{\mathrm{c}}$ & $11.33^{\mathrm{def}}$ & $12.38^{\mathrm{d}}$ \\
\hline 12 days $* 3$ hours & 50.50 & $1.58^{\mathrm{b}}$ & $13.12^{\mathrm{ab}}$ & $14.70^{\mathrm{b}}$ \\
\hline 12 days $*$ hours & 50.60 & $1.56^{\mathrm{b}}$ & $11.80^{\text {de }}$ & $13.36^{\mathrm{c}}$ \\
\hline 12 days $*$ 9 hours & 50.30 & $1.90^{\mathrm{a}}$ & $13.80^{\mathrm{a}}$ & $15.70^{\mathrm{a}}$ \\
\hline SEM & 0.0562 & 0.0639 & 0.2020 & 0.2593 \\
\hline p-value & 0.996 & 0.0001 & 0.0001 & 0.0001 \\
\hline
\end{tabular}

Note: *Means, within columns, for the main treatment effects or the interaction effects, with no common superscript, differ significantly $(\mathrm{P} \leq 0.05)$. ${ }^{* *}$ SEM $=$ Stander error of the mean.

\subsection{Fertility and Hatchability}

Table 2 demonstrates the effects of the egg fertility, hatchability of fertile and total eggs. There were no significant effects on the apparent percentage of fertility from the egg storage period, the pre-storage heating duration or the interaction between them. The hatchability of fertile and total eggs was significantly influenced by both the experimental factors and their interaction. Longer egg storage time resulted in a significant linear decrease in the hatchability of fertile and total eggs, irrespective of the length of the preheating. Overall, eggs heated for six hours had substantially higher hatchability of fertile and total eggs relative to non-heated or nine-hour heated eggs. Pre-storage heating of eggs in eggs stored for more than 4 days for six hours substantially improved hatchability (Table 2). During the storage time of four days, eggs heated for nine hours had significantly lower hatchability compared to the non-heated ones. Pre-storage eggs heated for six hours had higher hatchability when stored for four or eight days as compared to eggs stored for 12 days Table 2. The long storage or pre-storage heating eggs didn't affect apparent fertility in the present study. 
Table-2. The effects of storage period and pre-storage incubation and their interaction on fertility, hatchability and embryonic mortality of Dokki4 eggs.

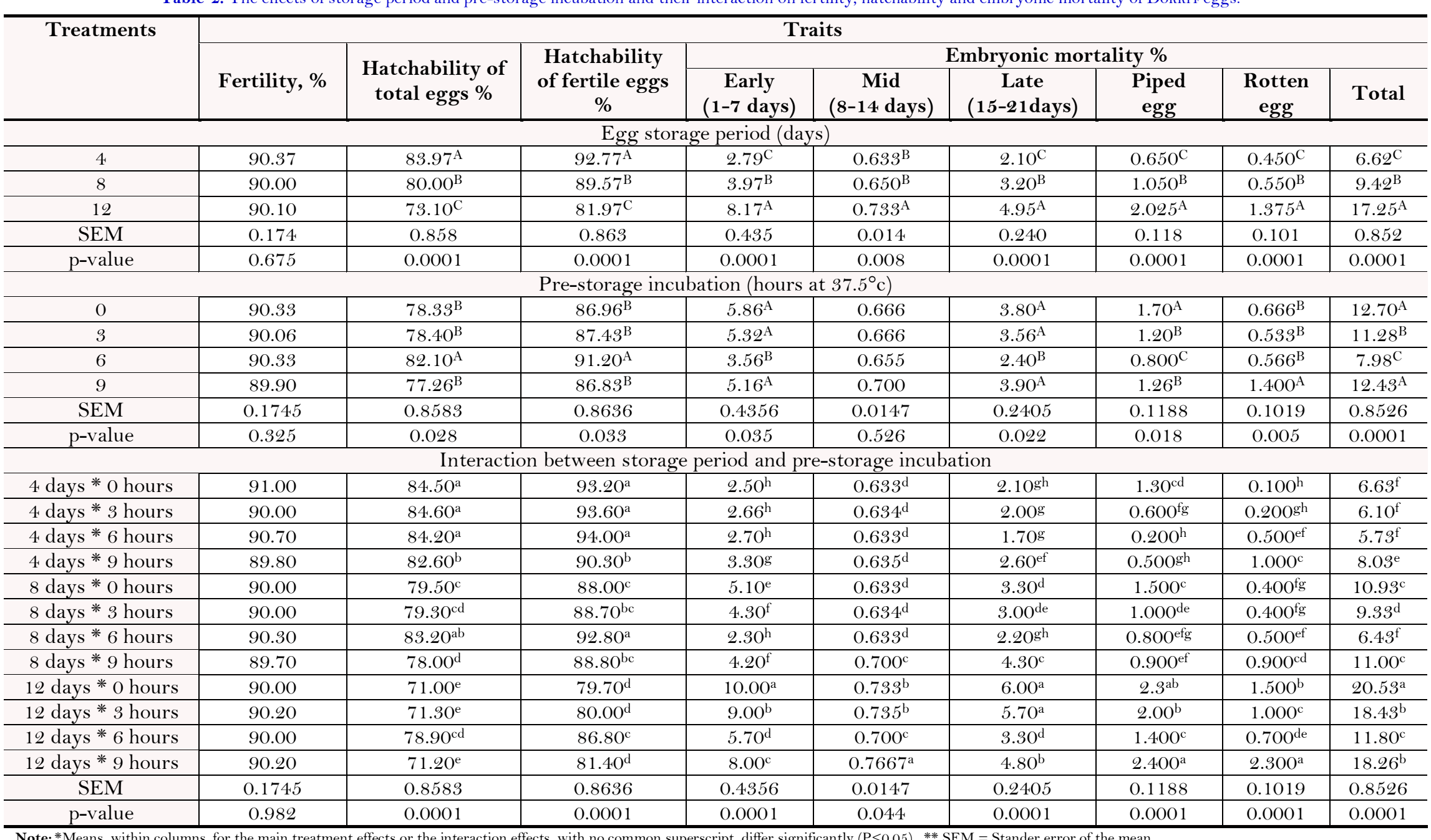




\subsection{Embryonic Mortality}

Early and late embryo mortality Table 2 above showed that eggs sorted for 12 days had significantly higher early and late mortality, piped eggs, rotted eggs and overall percentages of embryonic mortality relative to the other sorted period (4 days).

Table-3. The effect of storage period and pre-storage incubation and their combination on chick quality.

\begin{tabular}{|c|c|c|c|c|c|}
\hline \multirow[t]{3}{*}{ Treatments } & \multicolumn{5}{|c|}{ Traits } \\
\hline & \multicolumn{3}{|c|}{ Chick quality } & \multicolumn{2}{|c|}{ Day old chick quality measur ments } \\
\hline & Grade $\mathbf{A}^{1}$ & ${\text { Grade } B^{2}}$ & Grade $\mathbf{C}^{3}$ & Body weight $\mathrm{g}$ ) & Chick length $(\mathrm{cm})$ \\
\hline \multicolumn{6}{|c|}{ Egg storage period (days) } \\
\hline 4 & $94.46^{\mathrm{A} *}$ & $3.27^{\mathrm{B}}$ & $2.25^{\mathrm{B}}$ & $35.97^{\mathrm{A}}$ & 16.27 \\
\hline 8 & $93.30^{\mathrm{A}}$ & $3.58^{\mathrm{B}}$ & $3.11^{\mathrm{B}}$ & $35.20^{\mathrm{B}}$ & 16.22 \\
\hline 12 & $88.26^{\mathrm{B}}$ & $7.84^{\mathrm{A}}$ & $3.89^{\mathrm{A}}$ & $33.97^{\mathrm{C}}$ & 16.15 \\
\hline SEM & 0.532 & 0.413 & 0.200 & 0.146 & 0.025 \\
\hline p-value & 0.0001 & 0.0001 & 0.002 & 0.0001 & 0.141 \\
\hline \multicolumn{6}{|c|}{ Pre-storage incubation (hours at $37.5^{\circ} \mathrm{c}$ ) } \\
\hline $\mathrm{O}$ & $90.71^{\mathrm{B}}$ & $6.01^{\mathrm{A}}$ & $3.27^{\mathrm{A}}$ & 35.00 & 16.21 \\
\hline 3 & $92.41^{\mathrm{AB}}$ & $3.78^{\mathrm{C}}$ & $3.80^{\mathrm{A}}$ & 35.06 & 16.21 \\
\hline 6 & $94.11^{\mathrm{A}}$ & $4.10^{\mathrm{C}}$ & $1.78^{\mathrm{B}}$ & 35.13 & 16.25 \\
\hline 9 & $90.81^{\mathrm{B}}$ & $5.70^{\mathrm{B}}$ & $3.48^{\mathrm{A}}$ & 35.01 & 16.18 \\
\hline SEM $^{* *}$ & 0.5328 & 0.413 & 0.2002 & 0.146 & 0.025 \\
\hline p-value & 0.012 & 0.037 & 0.0001 & 0.989 & 0.845 \\
\hline \multicolumn{6}{|c|}{ Interaction between storage period and pre-storage incubation } \\
\hline 4 days $*$ o hours & $93.30^{\mathrm{cd}}$ & $4.13 \mathrm{de}^{\mathrm{e}}$ & $2.56^{\mathrm{de}}$ & $36.00^{\mathrm{a}}$ & 16.30 \\
\hline 4 days $* 3$ hours & $94.36^{\mathrm{b}}$ & $2.66^{\mathrm{g}}$ & $2.96^{\text {cde }}$ & $36.00^{\mathrm{a}}$ & 16.30 \\
\hline 4 days $* 6$ hours & $98.20^{\mathrm{a}}$ & $1.30^{\mathrm{h}}$ & $0.500^{f}$ & $36.00^{\mathrm{a}}$ & 16.30 \\
\hline 4 days * 9 hours & $92.00^{\mathrm{e}}$ & $5.00^{\text {cd }}$ & $3.00^{\text {cde }}$ & $35.90^{\mathrm{a}}$ & 16.20 \\
\hline 8 days $*$ o hours & $92.33^{\mathrm{e}}$ & $4.30^{\text {de }}$ & $3.36^{\mathrm{bcd}}$ & $35.20^{\mathrm{b}}$ & 16.20 \\
\hline 8 days $* 3$ hours & $93.70^{\text {bc }}$ & $3.10^{\mathrm{fg}}$ & $3.20^{\mathrm{cd}}$ & $35.20^{\mathrm{b}}$ & 16.20 \\
\hline 8 days $* 6$ hours & $94.33^{\mathrm{b}}$ & $3.00^{\mathrm{fg}}$ & $2.66^{\mathrm{de}}$ & $35.30^{\mathrm{b}}$ & 16.30 \\
\hline 8 days $* 9$ hours & $92.83^{\text {de }}$ & $3.93^{\mathrm{ef}}$ & $3.23^{\mathrm{cd}}$ & $35.13^{\mathrm{b}}$ & 16.20 \\
\hline 12 days $*$ o hours & $86.50^{\mathrm{h}}$ & $9.60^{\mathrm{a}}$ & $3.90^{\mathrm{bc}}$ & $33.80^{\mathrm{c}}$ & 16.13 \\
\hline 12 days $* 3$ hours & $89.16^{\mathrm{f}}$ & $5.60^{\mathrm{c}}$ & $5.23^{\mathrm{a}}$ & $34.20^{\mathrm{c}}$ & 16.13 \\
\hline 12 days * 6 hours & $89.80^{f}$ & $8.00^{b}$ & $2.20^{\mathrm{e}}$ & $34.80^{\mathrm{c}}$ & 16.16 \\
\hline 12 days * 9 hours & $87.60 \mathrm{~g}$ & $8.16^{\mathrm{b}}$ & $4.23^{\mathrm{b}}$ & $34.20^{\mathrm{c}}$ & 16.16 \\
\hline SEM & 0.5328 & 0.4137 & 0.2002 & 0.1466 & 0.0259 \\
\hline p-value & 0.0001 & 0.0001 & 0.0001 & 0.0001 & 0.920 \\
\hline
\end{tabular}

Note: *Means, within columns, for the main treatment effects or the interaction effects, with no common superscript, differ significantly $(\mathrm{P} \leq 0.05)$. ${ }^{*} *$ SEM $=$ Stander error of the mean.

1- Grade A = Good commercial Chicks. 2- Grade B = Bad Chicks. 3- Grade C = Very bad Chicks.

\subsection{Chick Quality}

Different metrics were used for assessing the chick quality. These indicators included a grade of commercial chick quality, chick body weight and 1day old chick length. All chick quality characteristics studied were significantly affected by both storage period and duration of pre-storage heating Table 3. Long storage time of eggs was associated with a decrease in the percentage of chicks in grade A, body weight and length of chicks, at one day. In comparison, the levels of Grade B and C chicks for eggs stored for more than four days were significantly higher than those stored for only four days. Pre-storage heating of eggs for six hours resulted in significant improvements in all characteristics of chick quality compared to unheated eggs Table 3. There were significant interactions for the grade of chicks between the storage period and the duration of incubation before storage. The data obtained indicated that the chicks produced from heated eggs for six hours and stored for 4-12 days had significantly higher percentages of A-grade chicks than non-heated eggs Table 3. Only when eggs were stored for four, eight or twelve days Table 3 was observed the significant improvement in grade A chick's percentage in the six-hour heating group as compared to three- or nine-hours heating group. When eggs were stored for 4, 8 or 12 days, chicks with a significantly heavier weight were produced by heating eggs for three, six or nine hours compared to the same storage period with unheated ones. The chicks hatched from six hours of heated eggs and kept for 4 to 12 days were considerably longer than those hatched from unheated or nine hours of heated eggs. No interaction between storage 
time and pre-incubation heating profile was observed chick length Table 3. Chicks of the 4-d storage time were longer than chicks of the 8 and 12-d storage time. Chick length reduced when storage time increased. The preincubation heating profile did not affect chick length.

\section{DISCUSSION}

\subsection{Egg Weight Loss}

Increasing duration of pre-incubation periods means increasing eggs exposure time for the incubation temperature leading to increased loss of egg weight because the pressure of water vapor increases as the duration of pre-incubation rises. In addition, prolonged storage time of the eggs has resulted in a decrease in cuticle consistency, which may contribute to increased water vapor pressure, raising the loss of egg weight [21]. Such findings are consistent with those reported by Reijrink, et al. [6] who observed that storage of commercial Cobb broiler breeder eggs for 3, 5, 8 or 12 days prior to hatching increased the percentage of LEW during storage by $0.24,0.53,0.74$ and 1.28 percent, respectively. Also, Reijrink, et al. [2] reported that the percentage of LEW during incubation and the percentage of total LEW for 4 hours pre-incubation was lower than for the 24 hours preincubation period.

\subsection{Fertility and Hatchability}

The two main treatments should not have affected fertility because fertilization would have occurred or would not have occurred before the eggs were exposed to the treatments. Fasenko, et al. [3]reported similar suggestions in chicken eggs, and Petek and Dikmen [11] in quail eggs. The latter authors found that the differences for the apparent fertility among the main groups of pre-storage heating and storage duration were not significant. Hatchability in Table 2, was substantially lower hatchability percentages of both fertile and total eggs were observed as storage periods increased because prolonged storage eggs leading to changes in egg components such as increased albumen $\mathrm{pH}$ and reduced albumen height and Haugh units [5] which decreased embryonic viability [22] because albumen structure is said to be a dominant factor in successful development of the germ from anaerobic to aerobic metabolism, thereby hatchability percentage decreased [23]. In the long storage period (12 days), hatchability percentage was increased after exposure of the eggs for pre-storage incubation compared to nonpre-storage incubation (control) eggs but was still significantly lower than the same pre-storage incubation level in the short stored period (4 days) may be because pre storage incubation provides more incubation time for the egg to hatch [3], but the changes in the internal egg quality (albumen) due to prolonged eggs stored (14 days) are not prevented by pre storage incubation [6]. Thus, in each pre-storage incubation procedure for the long storage period (12 days), the hatchability percentage is still significantly lower compared with the same amount of prestorage incubation over the short-stored period (4 days). Dokki4 eggs exposed to warming for six $\mathrm{h}$ during the long storage time (12 days) had higher and significant hatchability percentages of fertile and total eggs compared with the control and other pre-heating eggs for 3 and $9 \mathrm{~h}$ prior to eggs storage, may be because pre-incubation of eggs for $6 \mathrm{~h}$ prior to eggs storage for a long time (12 days) allowing the embryos to reach a developmental stage more suitable to survive the long storage period (12 days), which characterized by stopping embryonic development as measured by microscopic staging methods during eggs storage [24, 25] compared to the stages of embryos development that reach to it when pre-warming eggs for 0,10 and $15 \mathrm{~h}$ prior to eggs storage for 14 days. Our findings are in accordance with those reported by Fasenko, et al. [3], who demonstrated that pre-incubation periods before storage $6 \mathrm{~h}$ treatment for broiler breeder eggs took the majority of eggs embryos to a development stage [26] which hypoblast formation is complete and cell migration and differentiation are minimal [27], at this developmental stage, embryos are at a relatively quiescent state which promotes embryos survival to prolonged storage and embryonic death and are better able to withstand developmental arrest during prolonged storage of 14 days [3]. These embryos that displayed an enhanced development due to pre-storage heat treatment may be were 
better able to form an effective $\mathrm{pH}$ barrier between the inside of the embryo (pH ranges from 7.9 to $8.4 ;$ [28]) and its surroundings (albumen pH around 9.5, because after oviposition carbon dioxide is released from the embryo, resulting in an increase in albumen $\mathrm{pH}$ from about 7.6 to 9.5 within a short period of time, whereas the yolk remains slightly acidic, at a pH around 6.5 during early incubation than the less developed embryos (control) [2] due to that control treatment did not expose to any worming treatments and thereby its embryonic development which characterized by, area pellucida formation is complete [26], and the more advanced once because worming eggs for $12 \mathrm{~h}$ or $18 \mathrm{~h}$ allowing the majority of eggs embryos to reach an embryonic development Stage 3 or 4 which characterized by, primitive streak formation is approximately half complete or complete respectively [29] with extremely active periods of cellular division, migration and differentiation and do not respond favorably to developmental arrest during $14 \mathrm{~d}$ storage resulted in similar hatchability percentages of fertile and set eggs

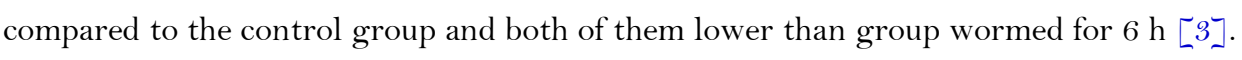

\subsection{Embryonic Mortality}

Extended egg-storage periods leads to; 1) allow albumen to degrade excessively. This deterioration allows the blastoderm to pass close to the shell of the egg resulting in early embryonic mortality resulting from dehydration during the early incubation phases [30] Increases sensitivity to suboptimal conditions of incubation which means that embryos are more sensitive to changes in temperature from storage to incubation time, leading to their higher early mortality [31] the number of viable embryonic cells is small as a function of long-term storage that may result in different steps in the development of the embryo at the beginning of the incubation period due to the lack of adequate cells in the embryo, unable to use the available $\mathrm{O}_{2}$ efficiently to break down the required nutrients in the yolk in order to release the energy needed for embryonic growth, leading to abnormal development or early embryonic death [13]. On the other hand, prolonged storage of eggs leads to reduced embryonic growth in some muscles such as the breast muscle (pectoralis major) and the hatching (complex) muscle, which are essential for metabolically mobilizing stored glycogen to help the embryo penetrate the shell of the egg and its membranes during the hatching process thereby increasing late embryonic mortality [32]. In the same storage period Table 2 , there was a steady rise of negligible mid-mortality values and significant values in early, late embryonic mortality, piped eggs, rotten eggs, and total percentages of embryonic mortality as the pre-incubation time before storage increased. This increase could be explained by Silva, et al. [31] who stated that increasing eggs exposure period for the incubation temperature before storage then storage temperature then incubation temperature being embryos were more susceptible to temperature changes leading to their higher embryo mortality at all studied periods.

\subsection{Chick Quality}

Pre-storage egg heating for 6 hours improved chick quality in terms of grade A percentage of chicks, chick weight and length, regardless of storage time compared to unheated eggs. These results are consistent with those reported by Yalçin and Siegel [33] and Reijrink, et al. [6]. Reijrink, et al. [2] who demonstrated that heating the hatching eggs before storage improved chick length. They said, this difference in chick length between the control and the pre-storage heated groups could be caused by a difference in hatch time. Pre-storage heating improved embryonic development, and thus pre-storage heated eggs hatched earlier than the control group chicks [6, 33]. This might explain why chick length and weight of the pre-storage heated eggs was higher at the moment of measurement than those of the non-heated eggs [18].

\section{CONCLUSIONS}

Based on our results, we can conclude that pre-storage heat treatment beneficially affects hatchability traits and chick quality, especially when hatching eggs are stored for long periods (12 days). 
Funding: This study received no specific financial support.

Competing Interests: The authors declare that they have no competing interests.

Acknowledgement: All authors contributed equally to the conception and design of the study.

\section{REFERENCES}

[1] K. Tona, F. Bamelis, B. De Ketelaere, V. Bruggeman, V. Moraes, J. Buyse, O. Onagbesan, and E. Decuypere, "Effects of egg storage time on spread of hatch, chick quality, and chick juvenile growth," Poultry Science, vol. 82, pp. 736-741, 2003. Available at: https://doi.org/10.1093/ps/82.5.736.

[2] I. Reijrink, R. Meijerhof, B. Kemp, and H. van den Brand, "Influence of egg warming during storage and hypercapnic incubation on egg characteristics, embryonic development, hatchability, and chick quality," Poultry Science, vol. 89, pp. 24702483, 2010. Available at: https://doi.org/10.3382/ps.2010-00798.

[3] G. Fasenko, V. Christensen, M. Wineland, and J. Petitte, "Examining the effects of prestorage incubation of turkey breeder eggs on embryonic development and hatchability of eggs stored for four or fourteen days," Poultry Science, vol. 80, pp. 132138, 2001. Available at: https://doi.org/10.1093/ps/80.2.132.

[4] K. Tona, O. Onagbesan, B. De Ketelaere, E. Decuypere, and V. Bruggeman, "Effects of age of broiler breeders and egg storage on egg quality, hatchability, chick quality, chick weight, and chick posthatch growth to forty-two days," Journal of Applied Poultry Research, vol. 13, pp. 10-18, 2004. Available at: https://doi.org/10.1093/japr/13.1.10.

[5] C. Lapao, L. Gama, and M. C. Soares, "Effects of broiler breeder age and length of egg storage on albumen characteristics and hatchability," Poultry Science, vol. 78, pp. 640-645, 1999. Available at: https://doi.org/10.1093/ps/78.5.640.

[6] I. Reijrink, R. Meijerhof, B. Kemp, E. Graat, and H. Van den Brand, "Influence of prestorage incubation on embryonic development, hatchability, and chick quality," Poultry Science, vol. 88, pp. 2649-2660, 2009. Available at: https://doi.org/10.3382/ps.2008-00523.

[7] D. Jones and M. Musgrove, "Effects of extended storage on egg quality factors," Poultry Science, vol. 84, pp. 1774-1777, 2005. Available at: https://doi.org/10.1093/ps/84.11.1774.

[8] K. Nahm, "Effects of storage length and weight loss during incubation on the hatchability of ostrich eggs (Struthio camuelus)," Poultry Science, vol. 80, pp. 1667-1670, 2001. Available at: https://doi.org/10.1093/ps/80.12.1667.

[9] M. Gucbilmez, S. Özlü, R. Shiranjang, O. Elibol, and J. Brake, "Effects of preincubation heating of broiler hatching eggs during storage, flock age, and length of storage period on hatchability," Poultry Science, vol. 92, pp. 3310-3313, 2013. Available at: https://doi.org/10.3382/ps.2013-03133.

[10] G. Fasenko, F. Robinson, A. Whelan, K. Kremeniuk, and J. Walker, "Prestorage incubation of long-term stored broiler breeder eggs: 1. Effects on hatchability," Poultry Science, vol. 80, pp. 1406-1411, 2001. Available at: https://doi.org/10.1093/ps/80.10.1406.

[11] M. Petek and S. Dikmen, "The effects of prestorage incubation of quail breeder eggs on hatchability and subsequent growth performance of progeny," Animal Research, vol. 53, pp. 527-534, 2004. Available at: https://doi.org/10.1051/animres:2004035.

[12] J. Hamidu, A. Rieger, G. Fasenko, and D. Barreda, "Dissociation of chicken blastoderm for examination of apoptosis and necrosis by flow cytometry," Poultry Science, vol. 89, pp. 901-909, 2010. Available at: https://doi.org/10.3382/ps.2009-00552.

[13] J. Hamidu, Z. Uddin, M. Li, G. Fasenko, L. Guan, and D. Barreda, "Broiler egg storage induces cell death and influences embryo quality," Poultry Science, vol. 90, pp. 1749-1757, 2011. Available at: https://doi.org/10.3382/ps.201 1-01361.

[14] J. Dymond, B. Vinyard, A. Nicholson, N. French, and M. Bakst, "Short periods of incubation during egg storage increase hatchability and chick quality in long-stored broiler eggs," Poultry Science, vol. 92, pp. 2977-2987, 2013. Available at: https://doi.org/10.3382/ps.2012-02816.

[15] S. A. Naji, G. A. Al-Qaisi, Z. T. Al-Danki, A. H. Al-Hilali, and Y. J. Jamil, Hatching and management of hatcheries. Baghdad, Iraq: Iraqi Poultry Producers Union, 2009.

[16] A. A. Abdel-Halim, F. Mohamed, A. Desoky, M. Elmenawey, and H. Gharib, "Effect of heating hatching eggs before or during storage on the alleviation of the negative effect of prolonged storage periods on hatchability," Egyptian Poultry Science Journal, vol. 35, pp. 703-717, 2015. 
[17] A. Lourens, "Heating eggs before storage," World Poultry, vol. 22, pp. 22-23, 2006.

[18] H. Willemsen, N. Everaert, A. Witters, L. De Smit, M. Debonne, F. Verschuere, P. Garain, D. Berckmans, E. Decuypere, and V. Bruggeman, "Critical assessment of chick quality measurements as an indicator of posthatch performance," Poultry Science, vol. 87, pp. 2358-2366, 2008. Available at: https://doi.org/10.3382/ps.2008-00095.

[19] SAS, SAS / stat user $\square s$ guide: Statistics cary. USA: SAS Institute Inc, 2009.

[20] B. D. Duncan, "Multiple range and multiple F. tests," Biometrics, vol. 11, pp. 1-42, 1955. Available at: https://doi.org/10.2307/3001478.

[21] K. De Reu, K. Grijspeerdt, Messens, W. Heyndrickx, M. Uyttendaele, J. Debevere, and L. Herman, "Eggshell factors influencing eggshell penetration and whole egg contamination by different bacteria, including Salmonella enteritidis," International Journal of Food Microbiology, vol. 112, pp. 253-260, 2006. Available at: https://doi.org/10.1016/j.ijfoodmicro.2006.04.011.

[22] K. Arora and I. Kosin, "Changes in the gross morphological appearance of chicken and turkey blastoderms during preincubation storage," Poultry Science, vol. 45, pp. 819-825, 1996.

[23] V. Christensen, M. Wineland, G. Fasenko, and W. Donaldson, "Egg storage effects on plasma glucose and supply and demand tissue glycogen concentrations of broiler embryos," Poultry Science, vol. 80, pp. 1729-1735, 2001. Available at: https://doi.org/10.1093/ps/80.12.1729.

[24] G. Fasenko, F. Robinson, and R. Hardin, "Variability in preincubation embryonic development in domestic fowl. 2. Effects of duration of egg storage period," Poultry Science, vol. 71, pp. 2129-2 132, 1992.

[25] M. Bakst and S. Gupta, "Preincubation storage of turkey eggs: Impact on rate of early embryonic development," British Poultry Science, vol. 38, pp. 374-377, 1997. Available at: https://doi.org/10.1080/00071669708418005.

[26] H. Eyal-Giladi and S. Kochav, "From cleavage to primitive streak formation: a complementary normal table and a new look at the first stages of the development of the chick: I. General morphology," Developmental Biology, vol. 49, pp. 321-337, 1976. Available at: https://doi.org/10.1016/0012-1606(80)90117-7.

[27] R. Bellairs, "The primitive streak," Anatomy and Embryology, vol. 174, pp. 1-14, 1986.

[28]J. Gillespie and S. McHanwell, "Measurement of intra-embryonic pH during the early stages of development in the chick embryo," Cell and Tissue Research, vol. 247, pp. 445-451, 1987. Available at: https://doi.org/10.1007/bfo0218326.

[29] V. Hamburger and H. L. Hamilton, "A series of normal stages in the development of the chick embryo," Journal of Morphology, vol. 88, pp. 49-92, 1951. Available at: https://doi.org/10.1002/jmor.1050880104

[30] J. Brake, T. Walsh, and S. Vick, "Hatchability of broiler eggs as influenced by storage and internal quality," Zootech Int, vol. 16, pp. 30-41, 1993.

[31] F. Silva, D. Faria, K. Torres, D. Faria Filho, A. Coelho, and V. Savino, "Influence of egg pre-storage heating period and storage length on incubation results," Brazilian Journal of Poultry Science, vol. 10, pp. 17-22, 2008. Available at: https://doi.org/10.1590/s1516-635x2008000100003.

[32] J. De Oliveira, Z. Uni, and P. Ferket, "Important metabolic pathways in poultry embryos prior to hatch," World's Poultry Science Journal, vol. 64, pp. 488-499, 2008. Available at: https://doi.org/10.1017/s0043933908000160.

[33] S. Yalçin and P. B. Siegel, "Developmental stability of broiler embryos in relation to length of egg storage prior to incubation," The Journal of Poultry Science, vol. 40, pp. 298-308, 2003. Available at: https://doi.org/10.2141/jpsa.40.298.

Views and opinions expressed in this article are the views and opinions of the author(s), Animal Review shall not be responsible or answerable for any loss, damage or liability etc. caused in relation to/arising out of the use of the content. 